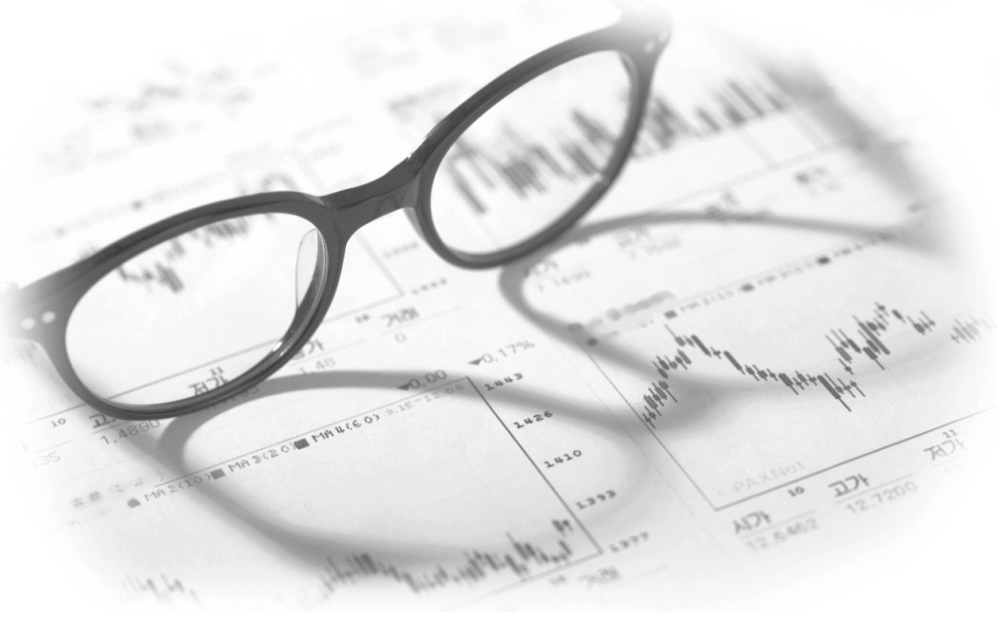

BLOOD RESEARCH

Volume 49 - Number 2 • June 2014

http://dx.doi.org/10.5045/br.2014.49.2.77

Perspective

\section{Direct oral anticoagulants in the treatment of cancer-associated venous thromboembolism}

\author{
Ho-Young Yhim ${ }^{1,2}$, M.D., Ph.D., Soo-Mee Bang ${ }^{3}$, \\ M.D., Ph.D. \\ ${ }^{1}$ Department of Internal Medicine, Chonbuk National \\ University Medical School, ${ }^{2}$ Research Institute of Clinical \\ Medicine, Chonbuk National University-Chonbuk National \\ University Hospital, Jeonju, ${ }^{3}$ Department of Internal Medicine, \\ Seoul National University Bundang Hospital, Seongnam, Korea
}

Venous thromboembolism (VTE), including deep vein thrombosis and pulmonary embolism $(\mathrm{PE})$, is a serious complication of cancer and its treatment. Patients with cancer have 4- to 7-fold higher risk of developing VTE than those without cancer [1]. Cancer patients with concurrent VTE have approximately $12 \%$ risk of bleeding during anticoagulation therapy and up to $25 \%$ annual risk of recurrent VTE [1]. The occurrence of VTE may also cause a delay or discontinuation of anti-cancer treatments, including chemotherapy and surgery [2]. Therefore, development of VTE in cancer patients has been associated with an increased risk of death [1]. In general, patients with VTE require anticoagulation therapy to prevent thrombus extension and death, which was largely associated with fatal PE, and to prevent recurrence in the long-term [2]. Traditionally, warfarin has been a common treatment strategy for patients with VTE; the use of warfarin in cancer patients, however, might be limited by complications of cancer and its treatment, including drug reactions, malnutrition, and the frequent need for dose adjustment
[3]. As a result, low-molecular-weight-heparin (LMWH) was introduced as a suitable alternative anticoagulant because of few drug interactions and lack of requirement for routine laboratory monitoring; thus, it has been actively investigated in the treatment of cancer-associated VTE. A decade ago, the results of the phase III CLOT trial, which compared initial and maintenance therapy with dalteparin to warfarin therapy after initial dalteparin treatment in patients with cancer-associated VTE, were reported [4]. In this study, long-term dalteparin therapy was significantly associated with lower rates of 6-month cumulative incidence of recurrent VTE (9\% vs. 17\%) [4]. Since this study, LMWH has been the standard of care for initial and long-term therapy of patients with cancer-associated VTE. However, LMWH for long-term therapy requires a daily subcutaneous injection for cancer patients with VTE, which makes them feel uncomfortable. Thus, unmet needs are still present in the management of cancer-associated VTE.

Direct oral anticoagulants (DOACs), including a direct thrombin inhibitor (dabigatran) and factor Xa inhibitors (rivaroxaban, apixaban, and edoxaban), are emerging alternatives for VTE treatment. They are potentially attractive for use in managing VTE because they can be administered with a fixed-dose orally and have a predictable drug effect, thus eliminating the needs for routine laboratory monitoring. The published trials to date, which include RE-COVER study for dabigatran [5, 6], EINSTEIN trials for rivaroxaban [7, 8], AMPLIFY study for apixaban [9], and HOKUSAI-VTE study for edoxaban [10], have shown that these DOACs are not inferior therapeutically and that they have similar or better safety profiles than standard anticoagulation therapy for VTE treatment, including VTE in cancer patients. Although demonstrating non-inferiority is not sufficient to change the standard of care, predictable drug effect, ease of administration, lack of routine monitoring, and very few drug or food interactions make DOACs attractive for the treatment of VTE, especially in

(9) This is an Open Access article distributed under the terms of the Creative Commons Attribution Non-Commercial License (http://creativecommons.org/licenses/by-nc/3.0) 6. which permits unrestricted non-commercial use, distribution, and reproduction in any medium, provided the original work is properly cited. 
Table 1. Proportion of cancer patients and eligibility criteria in major clinical trials regarding direct oral anticoagulants for the treatment of acute venous thromboembolism.

\begin{tabular}{|c|c|c|c|}
\hline Drug [references] & Total patients $(\mathrm{N})$ & Cancer patients $(\mathrm{N}, \%)$ & Eligibility criteria for cancer patients \\
\hline Rivaroxaban $[7,8,11]$ & 8,282 & $430(5.2 \%)$ & $\begin{array}{l}\text { Active cancer was eligible and was defined as the presence of } \\
\text { cancer at study entry. }\end{array}$ \\
\hline Apixaban [9] & 5,395 & $143(2.7 \%)$ & $\begin{array}{l}\text { Patients with cancer who would be treated for } \geq 6 \text { months with } \\
\text { low-molecular-weight-heparin therapy were ineligible. }\end{array}$ \\
\hline Dabigatran $[5,6,13]$ & 5,107 & $311(6.1 \%)$ & $\begin{array}{l}\text { Patients with a diagnosis of cancer (other than basal-cell or } \\
\text { squamous-cell carcinoma of the skin) within } 5 \text { years before } \\
\text { enrollment, with any treatment for cancer within } 5 \text { years } \\
\text { before enrollment or with recurrent/metastatic cancer were } \\
\text { eligible. }\end{array}$ \\
\hline Edoxaban $[10,12]$ & 8,292 & $\begin{array}{l}\text { Active cancer } 208(2.5 \%) ; \\
\text { history of cancer } 563(6.8 \%)\end{array}$ & $\begin{array}{l}\text { Patients with a history of cancer or with active cancer were } \\
\text { eligible if long-term low-molecular-weight-heparin treatment } \\
\text { was not planned. }\end{array}$ \\
\hline
\end{tabular}

cases of cancer-associated VTE [2]. In Korea, the use of rivaroxaban among DOACs is approved for the treatment of VTE, including for patients with cancer-associated VTE, and reimbursement is provided to those patients during the first 6 months of therapy. Although there are solid data for DOACs regarding VTE management, the value of these agents should not be overestimated in the treatment of VTE in cancer patients. First, there have been no studies specifically investigating the role of DOACs in treating cancer-associated VTE. Furthermore, all trials published to date actually included very few patients with cancer (Table 1). In addition, although subgroup analyses for cancer patients suggest clinical benefit similar to that noted in non-cancer patients with these agents, the small sample size of these exploratory analyses prevent any definitive conclusions [11-13]. Moreover, there was considerable heterogeneity in the definition and eligibility of cancer patients included in these trials (Table 1). RE-COVER I and II studies for dabigatran categorized patients as having cancer if they had a diagnosis of or any treatment for cancer within 5 years before study entry, regardless of tumor status at study entry [13]. Additionally, the AMPLIFY study for apixaban [9] and HOKUSAI-VTE study for edoxaban [10, 12] did not include patients who were planned for long-term ( $\geq 6$ months) LMWH therapy, which indicated that the researchers were likely to exclude patients with advanced/ metastatic cancer because these patients generally required indefinite anticoagulation therapy. Instead, patients with a prior history of cancer or VTE after major cancer surgery might have been included in these studies. Advanced/ metastatic cancer patients were the main group of interest in the clinical research of cancer-associated VTE, because they had a higher risk of VTE than those with localized disease or history of cancer [1]. Given that more than two-thirds of cancer patients had metastatic disease in the CLOT study, cancer patients in these major clinical DOACs trials to date did not represent the general population of cancer-associated VTE. Second, clinical data for DOACs showed that they were comparable with long-term warfarin therapy in efficacy and safety, but this was a well-known inferior agent compared to LMWH in patients with cancer [4]. Until now, no studies directly compared DOACs with LMWH in VTE treatment. DOACs should be re-investigated in this highly specific patient group. The Thrombosis Working Party of the Korean Society of Hematology is currently conducting a prospective study investigating the efficacy and safety of rivaroxaban in the treatment of cancer-associated VTE (clinicaltrials.gov \#NCT01989845). In this study, active cancer is defined as a diagnosis of cancer, other than basal cell or squamous cell carcinoma of the skin, within 6 months before enrollment; any treatment for cancer within the previous 6 months; or recurrent or metastatic disease. Therefore, this study will provide baseline data for future randomized phase III trials.

In the era of DOACs for the treatment of VTE, it is evident that they are absolutely appealing as a new class of agents because of their oral administration and minimal laboratory monitoring, and may add additional options to treat VTE in cancer patients. Further studies will be needed to establish the efficacy and safety of these new agents in this specific population. In future clinical trials, LMWH should be the comparator, because LMWH is the most effective treatment for cancer-associated VTE. Furthermore, these studies should be investigated in patient groups reflecting the real prothrombotic condition associated with active cancer and its treatment.

\section{REFERENCES}

1. Prandoni P, Lensing AW, Piccioli A, et al. Recurrent venous thromboembolism and bleeding complications during anticoagulant treatment in patients with cancer and venous thrombosis. Blood 2002;100:3484-8.

2. Wharin C, Tagalakis V. Management of venous thromboembolism in cancer patients and the role of the new oral anticoagulants. Blood Rev 2014;28:1-8.

3. Siegal DM, Garcia D. Anticoagulants in cancer. J Thromb Haemost 2012;10:2230-41. 
4. Lee AY, Levine MN, Baker RI, et al. Low-molecular-weight heparin versus a coumarin for the prevention of recurrent venous thromboembolism in patients with cancer. N Engl J Med 2003;349:146-53.

5. Schulman S, Kearon C, Kakkar AK, et al. Dabigatran versus warfarin in the treatment of acute venous thromboembolism. N Engl J Med 2009;361:2342-52.

6. Schulman S, Kakkar AK, Goldhaber SZ, et al. Treatment of acute venous thromboembolism with dabigatran or warfarin and pooled analysis. Circulation 2014;129:764-72.

7. Bauersachs R, Berkowitz SD, Brenner B, et al. Oral rivaroxaban for symptomatic venous thromboembolism. N Engl J Med 2010;363:2499-510.

8. Buller HR, Prins MH, Lensin AW, et al. Oral rivaroxaban for the treatment of symptomatic pulmonary embolism. N Engl J Med 2012;366:1287-97.

9. Agnelli G, Buller HR, Cohen A, et al. Oral apixaban for the treatment of acute venous thromboembolism. N Engl J Med 2013;369:799-808.

10. Buller HR, Decousus H, Grosso MA, et al. Edoxaban versus warfarin for the treatment of symptomatic venous thromboembolism. N Engl J Med 2013;369:1406-15.

11. Prins $M H$, Lensing AW, Bauersachs R, et al. Oral rivaroxaban versus standard therapy for the treatment of symptomatic venous thromboembolism: a pooled analysis of the EINSTEIN-DVT and PE randomized studies. Thromb J 2013;11:21.

12. Raskob GE, Buller H, Angchaisuksiri P, et al. Edoxaban for long-term treatment of venous thromboembolism in cancer patients. Blood 2013;122(ASH Annual Meeting):abst 211.

13. Schulman S, Eriksson H, Goldhaber SZ, et al. Influence of active cancer on the efficacy and safety of dabigatran versus warfarin for the treatment of acute venous thromboembolism: A pooled analysis from re-cover and re-cover II. Blood 2013;122(ASH Annual Meeting):abst 582. 